\title{
Estudio Morfológico e Histoquímico de las Glándulas Cefálicas de Bothrops alternatus (Ophidia, Viperidae)
}

\author{
Morphological and Histochemical Study of the Cephalic Glands \\ of Bothrops alternatus (Ophidia, Viperidae)
}

Ana Carolina Parpinelli; Ruberval A. Lopes; Miguel A. Sala; João Paulo M. Issa \& Túlio Roberto V. P. Lopes

PARPINELLI, A. C.; LOPES, R. A.; SALA, M. A.; ISSA, J. P. M. \& LOPES, T. R. V. P. Estudio morfológico e histoquímico de las glándulas cefálicas de Bothrops alternatus (Ophidia, Viperidae). Int. J. Morphol., 31(3):1026-1033, 2013.

RESUMEN: El objetivo del presente trabajo fue estudiar la histología de las glándulas cefálicas de la víbora de la cruz (Bothrops alternatus), identificar los tipos celulares y caracterizar histoquimicamente el producto de secreción. Con esta finalidad fueron usados ejemplares machos adultos de B. alternatus. Después del sacrificio, las glándulas cefálicas fueron fijadas en formol neutro al $10 \%$ e incluidas en parafina. Los cortes, de $6 \mu \mathrm{m}$ de espesor, fueron teñidos con hematoxilina y eosina, tricrómico de Masson y con técnicas histoquímicas para identificación de mucopolisacáridos y proteínas. Los resultados histológicos demostraron que las glándulas linguales, de veneno y accesorias son de tipo tubular, las glándulas labiales y premaxilar son tubuloacinares y la glándula de Harder es tubuloacinar compuesta. Las células mucosas de los adenómeros y conductos secretores de las glándulas linguales, labiales y premaxilar, así como las células de los conductos de la glándula de Harder, secretan sulfosialomucinas y mucopolisacáridos neutros. Las células mucoserosas de las glándulas linguales, labiales y premaxilar sintetizan mucopolisacáridos neutros, ácido siálico y radicales tirosina, cistina, cisteína, arginina y triptófano. Las células seromucosas de las glándulas de veneno, accesorias y de Harder producen polisacáridos neutros y radicales cistina, cisteína y triptófano, mientras que la glándula de Harder también sintetiza tirosina.

PALABRAS CLAVE: Morfología; Histoquímica; Glándulas cefálicas; Bothrops alternatus.

\section{INTRODUCCIÓN}

El género Bothrops, de la familia Viperidae, subfamilia Crotalinae, se caracteriza por la presencia de pequeñas escamas en la región dorsal de la cabeza y por la dentición solenoglifa. Todas las especies de esta familia poseen fosetas loreales, órganos termo-receptores localizados a ambos lados de la cabeza, entre el ojo y la nariz.

Bothrops alternatus (nombre vulgar: víbora de la cruz, crucera, yarará grande, cotiara, urutu) es una especie venenosa encontrada en el sudeste del Brasil, Paraguay, Uruguay y norte de Argentina. Los especímenes son razonablemente largos, pudiendo alcanzar 2,00 m de longitud, no obstante la mayoría raramente excede $1,20 \mathrm{~m}$.

El veneno de los ofidios del género Bothrops posee acción coagulante, necrotizante y hemorrágica. La acción coagulante se debe a su poder de activar los factores de coagulación, convertir la protrombina en trombina y transformar el fibrinógeno en fibrina (Denson et al., 1972). La capacidad necrotizante del veneno resulta de la acción citotóxica de sus fracciones proteolíticas sobre los tejidos (Gutiérrez \& Lomonte, 1989). De acuerdo con el volumen de veneno inoculado, puede ocurrir necrosis en el tejido adiposo y muscular y destrucción de las paredes vasculares. El veneno de Bothrops puede ocasionar hemorragias locales o sistémicas, afectando pulmón, riñón y cerebro. El edema local que acontece poco después de la picada, es provocado por la acción del veneno sobre el endotelio de los vasos. La acción vasculotóxica sistémica es debida a factores que causan la disolución de la membrana basal de los capilares y, posteriormente, provocan la rotura del endotelio (Barravieira \& Pereira, 1999).

Taub (1966) identificó 12 glándulas en la región cefálica de los ofidios, pero ninguna especie posee todas esas glándulas. En Bothrops alternatus fueron descritas ocho glándulas: infralabial, supralabial, sublingual, supralingual, premaxilar, glándula de veneno, glándula accesoria y glándula de Harder. 
El objetivo de este trabajo es estudiar histológicamente las glándulas cefálicas de Bothrops alternatus y caracterizar histoquímicamente los productos de secreción.

\section{MATERIAL Y MÉTODO}

Especímenes machos adultos de Bothrops alternatus, capturados en los municipios de Ribeirão Preto y Franca (São Paulo, Brasil), fueron decapitados bajo anestesia con éter. Después de resección de la piel y divulsión de los músculos, las glándulas labiales, linguales, premaxilar, venenífera y accesoria fueron disecadas cuidadosamente y la glándula de Harder fue extraída junto con el globo ocular. El material obtenido fue fijado en formol neutro al $10 \%$ por $24 \mathrm{~h} \mathrm{y}$, posteriormente, incluido en parafina.

Los cortes, de $6 \mu \mathrm{m}$ de espesor, fueron teñidos con hematoxilina y eosina y tricrómico de Masson para estudio histológico. Cortes adyacentes fueron utilizados para detección y caracterización histoquímica de las siguientes substancias:

Mucopolisacáridos neutros. Ácido peryódico-Schiff (PAS) (McManus, 1946), PAS después de digestión con a-amilasa (Spicer et al., 1967), PAS después de digestión con tripsina, PAS después de digestión con cloroformo + metanol y PAS después de acetilación (McManus \& Cason, 1950).

Mucopolisacáridos ácidos. Azul alcian (AB) a pH 0,5 (Lev \& Spicer, 1964), AB a pH 2,5 (Mowry \& Winkler, 1956), AB ( $\mathrm{pH} 2,5)$ después de metilación, $\mathrm{AB}(\mathrm{pH} 2,5)$ después de metilación + saponificación (Spicer \& Lillie, 1959), AB (pH $2,5)$ después de digestión con neuraminidasa (Spicer \& Warren, 1960), AB (pH 2,5) después de hidrólisis ácida (Quintarelli et al., 1961), $\mathrm{AB}$ (pH 2,5) después de digestión con hialuronidasa testicular (Quintarelli, 1963) y técnica combinada PAS + AB (pH 2,5) (Mowry \& Winkler).

Proteínas. Azul de bromofenol (Mazia et al., 1953), ninhidrina-Schiff (Yasuma \& Ichikawa, 1953), ninhidrinaSchiff después de desaminación (Burstone, 1955), ferricianuro férrico (Chévremont \& Frédéric, 1943), reacción de Millon (Lison, 1960), dimetilaminobenzaldehido (DMAB) (Lison), ácido perfórmico + DMAB, ácido perfórmico + $\mathrm{AB}(\mathrm{pH} 2,5)$ (Adams \& Sloper, 1956), amarillo naftol S (Deitch, 1955) y amarillo naftol $\mathrm{S}$ después de desaminación.

La caracterización histoquímica de las células secretoras de las glándulas cefálicas de B. alternatus fue basada en los criterios de Gabe \& St. Girons (1969).

\section{RESULTADOS}

Las glándulas con estructura histológica similar serán descritas en conjunto.

Glándulas supralabial, infralabial y premaxilar. La glándula supralabial se localiza junto a la mandíbula, debajo de las escamas labiales, y se extiende hasta la comisura labial. La glándula es dislocada y prensada lateralmente por la glándula de veneno. Está rodeada por un tejido fibroso denso vascularizado que emite septos que dividen el parénquima en varias regiones de orientación irregular, siguiendo su eje mayor. Es una glándula tubuloacinar, donde se reconocen dos porciones: la anterior, dispuesta en dos o más hileras, y la posterior, en una única hilera.

La pared de los túbulos secretores está compuesta por células mucosas y mucoserosas. Las células mucosas son claras, cilíndricas y alargadas, con citoplasma repleto de gránulos basófilos, y núcleos basales achatados, de cromatina densa. Las células mucoserosas, de forma variable, poseen escasos gránulos acidófilos citoplasmáticos y núcleos esféricos claros. La luz tubular es amplia y llena de secreción, que es vertida en conductos cortos revestidos por células epiteliales cúbicas bajas, de núcleos ovoides.

La glándula infralabial se extiende a lo largo de la superficie externa de la mandíbula. Está rodeada por una cápsula fibrosa bien vascularizada, que emite septos que la dividen en áreas parenquimatosas. Es una glándula tubuloacinar constituida por células mucosas y mucoserosas, con características semejantes a la glándula supralabial.

La glándula premaxilar se localiza en la unión de maxila y premaxila. Está compuesta de pequeñas áreas de parénquima, con adenómeros mixtos, formados por células mucosas cilíndricas de núcleos menores y gránulos citoplasmáticos basófilos, y células mucoserosas bajas de núcleos redondeados y gránulos citoplasmáticos acidófilos. El epitelio de los conductos secretores está formado por células claras, bajas, basófilas, con núcleos basales pequeños.

La histoquímica de estas tres glándulas demostró células mucosas con intensa reacción PAS, inalterada por la digestión con $\alpha$-amilasa, tripsina o cloroformo + metanol, pero bloqueada por la acetilación. Estas células también mostraron alcianofilia intensa a $\mathrm{pH} 2,5$ y débil a pH 0,5 . La reacción PAS + AB las tiñó en azul y púrpura (Fig. 1). La alcianofilia se mantuvo después de la metilación + saponificación y digestión con hialuronidasa, mas fue afectada por la hidrólisis ácida y por la digestión con neuraminidasa. 
Tabla I. Reacciones histoquímicas para mucopolisacáridos y proteínas en las glándulas labiales, linguales y premaxilar de Bothrops alternatus (M: células mucosas; MS: células mucoserosas).

\begin{tabular}{lccc}
\hline \multirow{2}{*}{ Método } & \multicolumn{3}{c}{ Glándulas labiales, linguales y premaxilar } \\
\cline { 2 - 4 } & \multicolumn{2}{c}{ Adenómeros } & Conductos \\
\cline { 2 - 4 } & M & MS & M \\
\hline PAS & +++ & ++ & +++ \\
Tripsina + PAS & +++ & ++ & +++ \\
Cloroformo + Metanol + PAS & +++ & + & +++ \\
Acetilación + PAS & +++ & ++ & +++ \\
AB 2,5 + PAS & - & - & - \\
AB 0,5 & A-V & P-A & A-V \\
AB 2,5 & + & - & + \\
Metilación + AB 2,5 & +++ & + & +++ \\
Metilación + Saponificación + AB 2,5 & - & - & - \\
Hidrólisis ácida + AB 2,5 & ++ & \pm & ++ \\
Neuraminidasa + AB 2,5 & + & \pm & + \\
Hialuronidasa testicular + AB 2,5 & + & + & + \\
Azul de bromofenol & +++ & ++ & - \\
Ninhidrina-Schiff & - & + & - \\
Desaminación + Ninhidrina-Schiff & - & + & - \\
Ferricianuro férrico & - & - & - \\
Millon & - & + & - \\
DMAB & - & + & - \\
Ácido perfórmico + DMAB & - & + & - \\
Ácido perfórmico + AB 2,5 & - & - & Reacción: \\
Amarillo naftol S & - & + & (++) Intensa \\
Desaminación + Amarillo naftol S & - & + & Moderada \\
\end{tabular}

Tabla II. Reacciones histoquímicas para mucopolisacáridos y proteínas en las glándulas de veneno, accesorias y de Harder de Bothrops alternatus (M: células mucosas; SM: células seromucosas).

\begin{tabular}{|c|c|c|c|c|}
\hline \multirow{3}{*}{ Método } & \multirow{3}{*}{$\begin{array}{c}\begin{array}{c}\text { Glándula de } \\
\text { veneno }\end{array} \\
\text { SM } \\
\end{array}$} & \multirow{3}{*}{$\begin{array}{c}\begin{array}{c}\text { Glándulas } \\
\text { accesorias }\end{array} \\
\text { SM } \\
\end{array}$} & \multicolumn{2}{|c|}{ Glándula de Harder } \\
\hline & & & Adenómeros & Conductos \\
\hline & & & SM & M \\
\hline PAS & +++ & ++ & ++ & +++ \\
\hline$\alpha$-amilasa + PAS & +++ & ++ & ++ & +++ \\
\hline Tripsina + PAS & ++ & + & + & +++ \\
\hline Cloroformo + Metanol + PAS & +++ & ++ & ++ & +++ \\
\hline Acetilación + PAS & - & - & - & - \\
\hline $\mathrm{AB} 2,5+\mathrm{PAS}$ & $\mathbf{P}$ & $\mathbf{P}$ & $\mathbf{P}$ & $\mathbf{V}$ \\
\hline AB 0,5 & - & - & - & + \\
\hline AB 2,5 & - & - & - & ++ \\
\hline Metilación + AB 2,5 & - & - & - & - \\
\hline Metilació n + Saponificación + AB 2,5 & - & - & - & + \\
\hline Hidrólisis ácida + AB 2,5 & - & - & - & + \\
\hline Neuraminidasa + AB 2,5 & - & - & - & + \\
\hline Hialuronidasa testicular $+\mathrm{AB} 2,5$ & - & - & - & + \\
\hline Azul de bromofenol & + & + & + & - \\
\hline Ninhidrina-Schiff & + & + & + & - \\
\hline Desaminación + Ninhidrina-Schiff & - & - & - & - \\
\hline Ferricianuro férrico & + & + & + & - \\
\hline Millon & - & - & + & - \\
\hline DMAB & + & + & + & - \\
\hline Ácido perfórmico + DMAB & - & - & - & - \\
\hline Ácido perfórmico + AB 2,5 & + & + & + & - \\
\hline Amarillo naftol S & + & + & + & - \\
\hline Desaminación + Amarillo naftol S & - & - & \pm & - \\
\hline
\end{tabular}


El producto de secreción de las células mucoserosas mostró reacción PAS positiva, resistente a la $\alpha$-amilasa, mas bloqueada por la tripsina. Las células mucoserosas exhibieron reacción $\mathrm{AB}$ a $\mathrm{pH}$ 2,5 positiva, sensible a hidrólisis ácida y a la digestión con neuraminidasa. Las técnicas para proteínas mostraron reacción moderada a intensa del producto de secreción.

Los conductos secretores están formados por células mucosas y su comportamiento histoquímico es similar al de las células mucosas de los adenómeros.

Glándulas supralingual y sublingual. La glándula supralingual se localiza dorsalmente a la vaina lingual y consiste de un par de glándulas tubulares con adenómeros constituidos por células mucosas altas con citoplasma granular basófilo.

La glándula sublingual se localiza en el piso de la cavidad bucal y es análoga a la supralingual, con adenómeros de células mucosas altas y citoplasma granular basófilo.

Ambas glándulas poseen células mucosas con intensa reacción PAS positiva, no afectada por la $\alpha$-amilasa, tripsina o cloroformo + metanol, mas inhibida por la acetilación. Estas células mostraron, aún, alcianofilia fuerte a pH 2,5 y débil a pH 0,5. La coloración PAS + AB las tiñó en azul-púrpura (Fig. 2). La alcianofilia se conservó después de metilación + saponificación y de digestión con hialuronidasa, mas fue reducida por la hidrólisis ácida y por la neuraminidasa.

Glándula de veneno y glándula accesoria. La glándula de veneno es de forma ovoide y se sitúa a ambos lados de la cabeza, desde la parte posterior del maxilar superior hasta la comisura labial. En la porción anterior, la glándula se adelgaza, continuándose en un conducto primario que, después de un corto trayecto, se dilata formando la glándula accesoria. Esta es menor que la glándula de veneno y constituye un depósito que controla el flujo de veneno, además de contribuir con varios productos para su dilución. La glándula accesoria se continúa en el conducto secundario, que vierte el veneno en el colmillo inyector.

La glándula de veneno de $B$. alternatus está rodeada por una cápsula de tejido conjuntivo denso que emite septos que separan y sirven de soporte a los túbulos secretores. Estos son largos y convergen de la región dorsal posterior a la región ventral anterior de la glándula. Están revestidos por un único estrato de células seromucosas cilíndricas de citoplasma granular acidófilo. La altura de las células varía según el contenido de veneno de los túbulos, altas en las glándulas vacías (Fig. 3) y achatadas en las glándulas repletas de veneno (Fig. 4). Sus núcleos son basales, redondeados y de cromatina escasa. La luz tubular muestra abundante secreción.

La glándula accesoria está formada por largos túbulos revestidos por un epitelio de células seromucosas cilíndricas bajas, con núcleos basales, fuertemente basófilos. Los túbulos confluyen oblicuamente en el conducto excretor de la glándula de veneno.

La histoquímica de las células seromucosas de las glándulas de veneno y accesoria demostró intensa reacción al PAS (Fig. 5), inalterada por la $\alpha$-amilasa o cloroformo + metanol, pero disminuida por la digestión con tripsina e inhibida totalmente por la acetilación. Estas células no se tiñeron con $\mathrm{AB}$ a pH 2,5 o pH 0,5. La coloración PAS + AB las tiñó en púrpura, mientras que mostraron reacción positiva para proteínas.

Glándula de Harder. Es una glándula túbuloacinar compuesta, localizada en la región posterior media de la órbita. Está envuelta por una cápsula fibrosa de tejido conjuntivo denso que emite finos septos que la subdividen en lóbulos. Los adenómeros son grandes, formados por células seromucosas cilíndricas altas, de núcleos redondeados basales y citoplasma con gránulos fuertemente acidófilos. Los conductos excretores se reúnen en un único conducto mayor, revestido por un epitelio de células cilíndricas altas débilmente acidófilas, que desemboca en la conjuntiva ocular.

Las células seromucosas de la glándula de Harder muestran reacción PAS positiva (Fig. 5), no afectada por la $\alpha$-amilasa o cloroformo + metanol, más abolida por la tripsina. Estas células no se tiñeron con $\mathrm{AB}$ (Fig. 6), pero revelaron reacción fuerte a moderada para proteínas.

Los conductos excretores poseen células mucosas PAS positivas, resistentes a la $\alpha$-amilasa, tripsina o cloroformo + metanol, y AB positivas a $\mathrm{pH} 0,5 \mathrm{o} \mathrm{pH} 2,5$, resistentes a la hidrólisis ácida, neuraminidasa o hialuronidasa. La técnica PAS + AB tiñó las células en azul-púrpura y las técnicas para proteínas fueron negativas.

\section{DISCUSIÓN}

Glándulas supralabial, infralabial y premaxilar. Según los criterios de Gabe \& St. Girons, los adenómeros de estas glándulas poseen células mucosas y mucoserosas. La naturaleza mixta de los adenómeros de las glándulas labiales fue referida por Taub (1967a, 1967b), Gabe \& St. Girons, Zago (1971), Lopes et al. (1973, 1981) y Costa et 


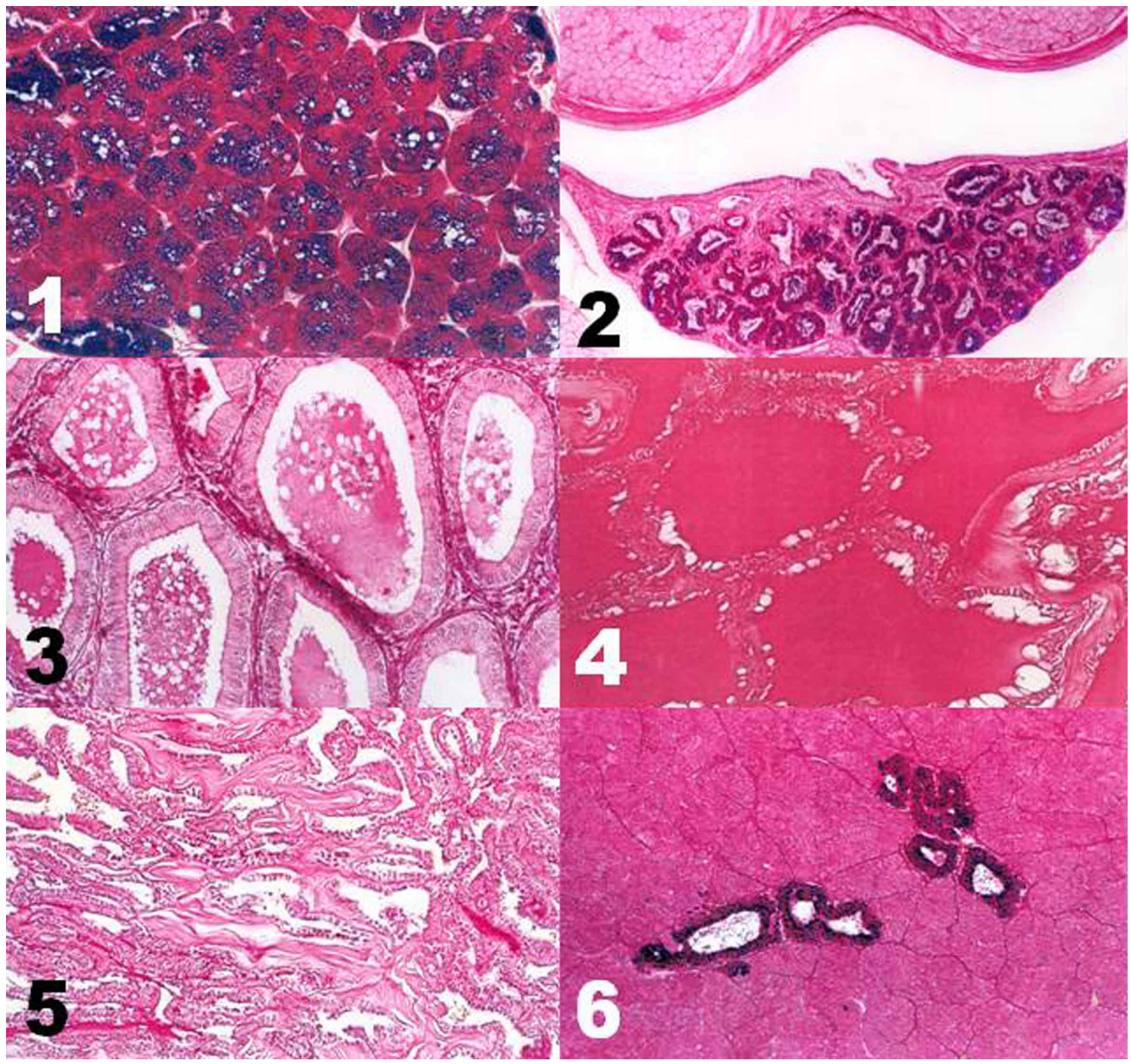

Fig. 1. Aspecto histológico de la glándula supralabial de B. alternatus. Notar el producto de secreción PAS y AB positivo. PAS + AB a pH 2,5 (200x).

Fig. 2. Aspecto histológico de la glándula sublingual de B. alternatus. Notar la predominancia de la coloración por el $\mathrm{AB}$. $\mathrm{PAS}+\mathrm{AB}$ a pH 2,5 (200x).

Fig. 3. Aspecto histológico de la glándula de veneno de $B$. alternatus. Glándula con adenómeros vacíos y epitelio glandular con células más altas. PAS (200x).

Fig. 4. Aspecto histológico de la glándula de veneno de B. alternatus. Adenómeros repletos de veneno intensamente PAS positivo, con epitelio glandular achatado. PAS (200x).

Fig. 5. Aspecto histológico de la glándula accesoria de B. alternatus. Adenómeros PAS positivos. PAS + AB a pH 2,5 (200x).

Fig. 6. Aspecto histológico de la glándula de Harder de B. alternatus. Adenómeros PAS positivos y conductos teñidos por el PAS y AB. PAS $+\mathrm{AB}$ a pH 2,5 (200x).

al. (1980). Los túbulos secretores tienen una pared formada por células mucosas y mucoserosas y una luz amplia, repleta de secreción. Las células mucosas poseen reacción PAS positiva inmune a la $\alpha$-amilasa, tripsina y cloroformo + metanol, mas bloqueada por la acetilación, revelando la presencia de mucopolisacáridos con grupos 1,2-glicol sulfatados y carboxilados, lo que se confirma por su coloración después de metilación + saponificación y digestión con hialuronidasa. Esas células exhibieron también fuerte alcianofilia, bloqueada por la metilación + saponificación, 
revelando mucopolisacáridos complejos con grupo ácido carboxilado, que la digestión con neuraminidasa y la hidrólisis ácida demostró ser ácido siálico. El bloqueo de la reacción al $\mathrm{AB}$ por la hialuronidasa evidencia la presencia de sulfato de condroitina A, B y/o C. La reacción positiva al $\mathrm{AB}(\mathrm{pH} \quad 0,5)$ revela la existencia de mucopolisacáridos ácidos. Resultados similares fueron relatados por Gabe \& St. Girons en Boidae y Colubridae, Zago en Boidae, Colubridae y Viperidae, Barros et al. (1973), en Boidae y Lopes et al. $(1973,1974)$ en Elapidae y Viperidae.

La histoquímica de las células mucoserosas de las glándulas labiales señala la presencia de glicoproteínas (mucopolisacáridos sulfatados neutros y ácidos, ácido siálico y proteínas). Resultados semejantes fueron relatados por Zago, Costa et al., y Lopes et al., (1981). Entre las substancias AB positivas se caracterizaron mucopolisacáridos ácidos sulfatados y ácido siálico. Las primeras poseen distribución más limitada, al contrario del ácido siálico que se manifestó en todas las glándulas examinadas, confirmando la opinión de que las glándulas salivales siempre poseen sialomucinas (Gottschalk, 1966).

La glándula premaxilar de $\mathrm{B}$. alternatus está constituida por células mucosas y mucoserosas. Para Taub (1966), la glándula sería puramente mucosa. Su estructura, localización y embriología sugieren que se trata de una expansión frontal de la supralabial (Taub, 1966)

Las células mucosas de la glándula premaxilar sintetizan mucopolisacáridos neutros y sulfosialomucinas, mientras que las mucoserosas producen glicoproteínas (mucopolisacáridos neutros y ácidos sulfatados, ácido siálico y proteínas con radicales $\alpha$-amino, cisteína, tirosina, triptófano y arginina), confirmando los resultados de Lopes et al. $(1981,1982)$ en Leimadophis viridis y Philodryas patagoniensis, respectivamente.

Glándulas supralingual y sublingual. Las glándulas linguales están formadas por células mucosas, cuya secreción es constituida por mucopolisacáridos neutros y sulfosialomucinas.

La glándula sublingual de $B$. alternatus es una glándula tubular, única, localizada en el piso de la boca. Entre los ofidios, Typhlops posee un par de glándulas sublinguales largas y ramificadas, cada una de ellas con un conducto único que se abre en el extremo rostral. En Leptotyphlops dulcis existe un par de pequeñas glándulas sublinguales cuya secreción es rica en mucinas ácidas (Kochva, 1978). La glándula sublingual de Boidae consiste de 6 a 8 túbulos similares, largos y ramificados, que desembocan en la extremidad rostral de la glándula. En Xenopeltis unicolor hay una pequeña glándula adicional en cima de cada sublingual (Kochva).

Las células mucosas de las glándulas linguales mostraron fuerte reacción al PAS, inmune al tratamiento con $\alpha$-amilasa, tripsina o cloroformo + metanol, pero inhibida por la acetilación. Esas células revelaron fuerte reacción al $\mathrm{AB}$ a pH 2,5 y débil a pH 0,5, afectadas por la hidrolisis acida y por la digestión con neuraminidasa, indicando la presencia de ácido siálico. La combinación PAS + AB tiñó las células mucosas en azul-púrpura, revelando una secreción constituida por mucopolisácaridos con grupos 1,2glicol sulfatados y carboxilados. Estos resultados fueron confirmados por la coloración de las células después de metilación + saponificación y digestión con hialuronidasa.

Glándulas de veneno y accesoria. Estas glándulas poseen células seromucosas que revelan intensa reacción PAS, inalterada por la $\alpha$-amilasa o cloroformo + metanol, reducida por la tripsina y bloqueada por la acetilación, y que no se tiñen con $\mathrm{AB}$ a pH 2,5 o 0,5. La coloración combinada PAS + AB las tiñen en púrpura, mientras que las técnicas para proteínas son positivas. Así, la secreción de las células seromucosas está compuesta por un complejo carbohidrato-proteínas (mucopolisacáridos neutros y radicales a-amino, triptófano, cistina, cisteína y arginina).

La glándula de veneno de $B$. jararaca posee células seromucosas que secretan un producto similar al de $B$. alternatus, mientras que la glándula accesoria posee células mucosas, productoras de mucopolisacáridos neutros y ácidos, y células mucoserosas, que secretan un complejo carbohidrato-proteínas (Lopes et al., 1974).

Glándula de Harder. Esta glándula está bien desarrollada en serpientes. Su función es lubrificar los ojos y, en algunos reptiles, ejerce la regulación osmótica (Chieffi et al., 1996).

Las células seromucosas de la glándula de Harder mostraron reacción PAS positiva inmune a la digestión con $\alpha$-amilasa o cloroformo + metanol pero sensible a la tripsina; reacción negativa al $\mathrm{AB}$ y reacción de fuerte a regular para proteínas, revelando la presencia de mucopolisacáridos con grupo 1,2-glicol y proteínas. Las células mucosas de los conductos exhibieron reacción al PAS inmune a la $\alpha$-amilasa, cloroformo + metanol o tripsina, y al $\mathrm{AB}$, resistente a la hidrólisis ácida, neuraminidasa e hialuronidasa, mientras que el PAS $+\mathrm{AB}$ tiñó las células en azul-púrpura y las técnicas para proteínas fueron negativas, revelando mucopolisacáridos con grupos 1,2-glicol sulfatados y carboxilados. 
PARPINELLI, A. C.; LOPES, R. A.; SALA, M. A.; ISSA, J. P. M. \& LOPES, T. R. V. P. Morphological and histochemical study of the cephalic glands of Bothrops alternatus (Ophidia, Viperidae). IInt. J. Morphol., 31(3):1026-1033, 2013.

SUMMARY: The aim of this paper was to study the histology of the cephalic glands of the snake Bothrops alternatus, identifying the cell types and characterize histochemically the secretion product. For this purpose we used male adult specimens of $B$. alternatus. After slaughter, the cephalic gland was fixed in 10\% neutral formalin and embedded in paraffin-wax. Histological sections, $6 \mu \mathrm{m}$ thick, were stained with hematoxylin and eosin, Masson trichrome and histochemical techniques to identify mucosubstances and proteins. Histologically they were identified tubuloacinar composed glands (Harderian gland), tubuloacinar glands (upper and lower lip and premaxillary glands) and tubular (supralingual, sublingual, venom, and accessory glands). The mucous cells of the acini of the upper and lower lip glands and of the premaxillary gland, the secretory ducts of these glands and ducts of the Harderian gland secrete sulfosialomucins and neutral mucosubstances. Mucoserous cells of upper and lower lip glands and premaxillary gland secrete neutral mucosubstances, sialic acid and protein radicals tyrosine, cystine, cysteine, arginine and tryptophane. Seromucous cells of venom, accessories and Harderian glands secrete neutral mucosubstances and protein radicals cystine, cysteine and tryptophan, whereas the seromucous cells of the Harderian gland also secrete the tyrosine radical.

KEY WORDS: Morphology; Histochemistry; Cephalic glands; Bothrops alternatus.

\section{REFERENCIAS BIBLIOGRÁFICAS}

Adams, C. W. \& Sloper, J. C. The hypothalamic elaboration of posterior pituitary principles in man, the rat and dog: histochemical evidence derived from a performic acidAlcian blue reaction for cystine. J. Endocrinol.,13(3) :221-8, 1956.

Barravieira, B. \& Pereira, P. C. M. Acidentes por serpentes do gênero Bothrops. In: Barravieira, B. Venenos: aspectos clínicos e terapêuticos dos acidentes por animais peçonhentos. Rio de Janeiro, EPUB, 1999. pp.261-80.

Barros, J. M.; Lopes, R. A.; Campos, G. M. \& Daruge, A. D. Estudo morfológico e histoquímico de polissacarídeos em glândulas cefálicas de Eunectes marinus (Ophidia, Boidae). Cienc. Cult., 25:151-6, 1973.

Burstone, M. S. An evaluation of histochemical methods for protein groups. J. Histochem. Cytochem., 3(1):3249,1955 .

Chèvremont, M. \& Fréderic, J. Une nouvelle methode histochimique de mise en evidence des substances à fonction sulfhydrile. Arch. Biol., 54:589-605, 1943.

Chieffi, G.; Baccari, G. C.; Di Matteo, L.; d'Istria, M.; Minucci, S. \& Varriale, B. Cell biology of the harderian gland. Int. Rev. Cytol., 168:1-80,1996.

Costa, J. R. V.; Lopes, R. A.; Piccolo, A. M.; Campos, S. M. \& Petenusci, S. O. Estudo morfológico e histoquímico das glândulas labiais e de Harder de Mastigodryas bifossatus (Ophidia, Colubridae). Rev. Bras. Biol., 40(2):349-55, 1980.
Deitch, A. D. Microspectrophotometric study of the binding of the anionic dye, naphthol yellow $\mathrm{S}$, by tissue sections and by purified proteins. Lab. Invest., 4(5):324-51, 1955.

Denson, K. W.; Russell, F. E.; Almagro, D. \& Bishop, R. C. Characterization of the coagulant activity of some snake venoms. Toxicon, 10(6):557-62, 1972.

Gabe, M. \& St. Girons, M. Donnes histologiques sur les glandes salivaires des lépidosauriens. Mem. Mus. Nat. Hist. Nat., 58:1-112, 1969.

Gottschalk, A. Glucoproteins: their composition, structure and function. Amsterdam, Elsevier, 1966.

Gutiérrez, J. M. \& Lomonte, B. Local tissue damage induced by Bothrops snake venoms. A review. Mem. Inst. Butantan, 51:211-23, 1989.

Kochva, E. Oral glands of Reptilia. In: Gans, C. \& Gans, K. A. (Eds.). Biology of the Reptilia. London and New York, Academic Press, 1978.

Lison, L. Histochimie et cytochimie animals: Principes et méthodes. 3ème éd. Paris, Gauthier-Villars, 1960.

Lopes, R. A.; Valeri, V.; Campos, G. M.; Lopes, O. V. P. \& Faria, R. M. Étude histochimique des mucopolysaccharides des glandes céphaliques de Micrurus corallinus (Ophidea, Elapidae). Ann. Histochim., 18(2):131-9, 1973.

Lopes, R. A.; Oliveira, C.; Campos, M. N.; Campos, S. M. 
\& Birman, E. G. Morphological and histochemical study of cephalic glands of Bothrops jararaca (Ophidia, Viperidae). Acta Zool., 55(1):17-24, 1974.

Lopes, R. A.; Costa, J. R. V.; Petenusci, S. O. \& Contrera, M. G. D. The salivary glands of Leimadophis viridis (Guther, 1862) (Ophidea, Collubridae): A morphological, morphometric and histochemical study. Monit. Zool. Ital. (NS), 15:249-61, 1981.

Lopes, R. A.; Contrera, M. G. D.; Costa, J. R. V.; Petenusci, S. O. \& Lima-Verde, J. S. Les glandes salivaires de Philodryas patagoniensis (Girard, 1857) (Ophidea, Colubridae). Étude morphologique, morphometrique et histochimique. Arch. Anat. Microsc. Morphol. Exp., 71:175-82, 1982.

Mazia, D.; Brewer, P. A. \& Alfert, M. The cytochemical staining and measurement of protein with mercuric bromophenol blue. Biol. Bull., 104(1):57-67, 1953.

McManus, J. F. \& Cason, J. E. Carbohydrate histochemistry studied by acetylation techniques. I. Periodic acid methods. J. Exper. Med.,91(6):651-4, 1950.

McManus, J. F. Histological demonstration of mucin after periodic acid. Nature, 158:202, 1946.

Mowry, R. W. \& Winkler, C. H. The coloration of acidic carbohydrates of bacteria and fungi in tissue sections with special reference to capsules of Cryptococcus neoformans, Pneumococcus and Staphylococcus. Am. J. Pathol., 32:628-9, 1956.

Quintarelli, G. Masking action of Basic proteins on sialic acid carboxyls in epithelial mucins. Experientia, 19:230$1,1963$.

Quintarelli, G.; Tsuiki, S.; Hashimoto, Y. \& Pigman, W. Studies of sialic acid containing mucin in bovine submaxillar and rat sublingual glands. J. Histochem. Cytochem., 9:176-83, 1961.

Spicer, S. S. \& Warren, L. The histochemistry of sialic acid containing mucoproteins. J. Histochem. Cytochem., 8:135-7, 1960.

Spicer, S. S. \& Lillie, R. D. Saponification as a means of selectively reversing the methylation blockade of tissue basophilia. J. Histochem. Cytochem., 7:123-5, 1959.

Spicer, S. S.; Horn, R. G. \& Leppi, T. J. Histochemistry of connective tissue mucopolys-sacharides. In: Wagner, B.
M. \& Smith, D. E. (Eds.). The connective tissue. International Academy of Pathology Monograph 7. Baltimore, Williams \& Wilkins, 1967. pp.251-303.

Taub, A. M. Ophidian cephalic glands. J. Morphol., 118(4):529-42, 1966.

Taub, A. M. Comparative histological studies on Duvernoy's gland of colubrid snakes. Bull. Amer. Mus. Nat. Hist., 138:1-50, 1967a.

Taub, A. M. Systematic implications from the labial glands of the Colubridae. Herpetologica, 23:145-8, 1967b.

Yasuma, A. \& Ichikawa, T. Ninhydrin-Schiff and alloxanSchiff staining; a new histochemical staining method for protein. J. Lab. Clin. Med., 41(2):296-9, 1953.

Zago, D. A. Estudo morfológico e histoquímico de glândulas salivares relacionadas com a evolução da função venenosa nos ofídios. Tese de Doutorado, Departamento de Histologia e Embriologia do Instituto de Ciências Biomédicas, Universidade de São Paulo, 1971.

Dirección para Correspondencia:

Prof. Dr. Miguel Ángel Sala

Faculdade de Odontologia de Ribeirão Preto

Universidade de São Paulo

Avenida do Café s/n

CEP 14040-904

Ribeirão Preto - SP

BRAZIL

Email: masdmatt@gmail.com

Received:

Accepted: 